\title{
Research on Internet Development and the Value-added Path of Manufacturing Value
}

\author{
ZHI Guolin ${ }^{1, a}$ \\ ${ }^{1}$ Beijing Jiaotong University, Beijing, China
}

\begin{abstract}
In the context of the rapid development of global value chain theory, "Internet" as the main feature of digital trade has bred greater opportunities for international cooperation and has become a driving force for the reconstruction of global value chains. This paper studies the relationship between the development of the Internet and the reconstruction of the value chain, verifies the evolution path of the industry's added value through theoretical derivation, and answers the impact of the development of the Internet on the evolution path of the smile curve. The results show that the "smile curve" is not a necessary feature of the upgrade of the manufacturing value chain. Some industrial value chain upgrades the form of a "Muslim curve", and the Internet can affect the value added of the manufacturing industry's export value through three ways.
\end{abstract}

\section{Introduction}

The combination of the development of the Internet and the Internet has greatly changed the structure of international trade and the added value of different industries. It has been transformed into the continuous expansion of $5 \mathrm{G}$ communication technology. The gap between the development of the Internet and the countries with earlystage development has further widened. It is necessary to form new comparative advantages, so that the traditional geographical separation and "fine" division of labor have changed.

The value chain theory studies the entire process of raw materials, semi-finished products and intermediate products, until final consumption and recycling, and the development of the Internet can ensure the timely transmission of information, which has a "multiplier effect" on reducing transaction costs. The value chain theory system is used to study the Internet The impact of development on specific industries is very persuasive.

\section{Literature review}

The interdependence between the Internet and global trade has always been a hot issue of social concern; in recent years, the decomposition of added value and the calculation of global value chains have also made considerable progress. Putting the two in the same research framework can decompose and refine the role of the Internet in promoting various industries, and explain the mechanism and impact of the development of the Internet more accurately.

\subsection{Internet Development Research Review}

The academic community generally believes that the development of the Internet can significantly promote the direct costs of a country's trade (such as transaction costs, information costs, and communication costs) and time (indirect) costs (such as transportation time savings and customs declaration time savings). Bakos [1], Anderson and Wincoop [2] first proved that the use of the Internet reduced the cost of communication and information search, and formed a trade creation effect; Melitz [3] analyzed the Internet in the framework of the heterogeneous trade theoretical model The mechanism of reducing the fixed and variable costs of enterprises, leading to the marginal and intensive marginal growth of international trade. In short, as an important infrastructure of the information society, the Internet has become a source of a country's comparative advantage in exports. The development of the Internet has a significant role in promoting the growth of trade flows among countries.

\subsection{A Summary of Studies on the Relationship between Global Value Chain and Internet Development}

For the study of the relationship between the Internet and the global value chain, the academic community mostly conducts research from two aspects. One is to use the development of the global value chain as a background to explore the impact of Internet development on specific industries, such as cross-border logistics, agriculture, and productivity. Service industry, etc. The second is to explore the impact of Internet development on a country's international trade and global value chain upgrade. This article mainly discusses the second part in detail. 
According to the "smile curve" theory, as the development of the Internet promotes the upgrading of the global value chain of the manufacturing industry, as the international division of labor system becomes more and more refined, the shape of the smile curve becomes more and more steep, and the outsourcing and source links extend The added value difference of the links will become larger and larger, which means that the expansion from the outsourcing link to the source link and the extension link can enhance the position of the manufacturing enterprise in the entire value chain. The academic circles gradually put forward different views, thinking that with the improvement of the "Internet + " system, the degree of involvement in the manufacturing industry will be further deepened, and the boundaries of each industrial chain link will be completely eliminated, making enterprises abandon the traditional vertical division of labor system and no longer engage in $\mathrm{R} \& \mathrm{D}$, Manufacturing and marketing services have caused the smile curve to evolve into a straight line. Some scholars also believe that the Internet can promote the horizontalization of the smile curve through direct channels such as disintermediation, increasing product technical content, opening up marketing channels, restructuring the value chain, and building platforms.

Looking back at the value chain theory, it is generally believed that the development of the industrial Internet will promote the reconstruction of the industrial value chain and change the value added of different industries. However, to what extent the Internet has affected the upstream, midstream and downstream industries in the value chain and how it will affect the change of the smile curve, few people in the academic world have studied it.

\section{Mechanism research and hypothesis}

\subsection{Industrial Internet and Value Added Curve}

Smile curve theory analyzes the role of manufacturing industry in the global production distribution process and the relationship of value added from the perspective of the division of labor in the value chain. Under the trend of rapid integration of the Internet, how to upgrade the value chain, there are different voices in academia. According to the transition path of traditional value chain value-added, Johnson RC, Noguera G [4] believes that the gradual rise of the national value chain will make the link in the middle of the smile curve closer to the marketing and R\&D links at both ends, increasing profits and added value; Koopman R, Powers W, Wang Z [5] put forward different voices, believing that the intermediary role of the Internet has the most obvious role in promoting the midstream of the value chain, and in extreme cases may promote the leveling of the smile curve. Finally, according to the Musashi curve proposed by Nakamura Suehiro, the distribution of industrial value added at each link may not conform to the smile curve, providing a new research perspective for value added and industrial upgrading.

\subsection{Industrial Internet and Value Chain}

Classical global value chain theory believes that the lower global value chain status is an important reason for the low rate of world intermediate goods export processing enterprises; the embedding theory also believes that the deeper the industry's global value chain is embedded, The more you can strengthen the ability to control the elements, and then enhance the added value and status of an industry. In the process of the Internet's promotion of the added value of the manufacturing industry, embedding in the global value chain can also improve the status of the country through knowledge spillover effects.

\subsection{Theoretical assumptions}

- Hypothesis 1: The development of the Internet will have an impact on the upstream, midstream and downstream industries of the value chain, promoting the increase in value added. The upstream R\&D link with higher capital endowments and the downstream sales link with higher labor endowments are less affected by Internetization. In the middle of the value chain, the manufacturing sector may be more suitable for Internet upgrades.

- Hypothesis 2: There is a positive relationship between the degree of Internet development among countries and the length and embeddedness of the value chain. The higher the degree of Internet development, the more able to enhance the status of the industry's global value chain.

- Hypothesis 3: The higher the degree of Internet development among countries, the higher the degree of embedding of countries in the global value chain.

\section{Research methods and procedures}

\subsection{Theoretical analysis}

\subsubsection{Theoretical model establishment and hypothesis}

The horizontal axis of the smile curve represents the link that should be in the industrial value chain. The vertical axis measures the industrial value-added rate. In order to understand the internal mechanism of the Internet and value chain upgrade, this paper is based on the introduction of the Cobb Douglas production function of technological development level. Connaught model as the basic framework for analysis. Because the model has certain practical factors, the following assumptions are made:

- $\quad$ Premise and Hypothesis 1: The fixed scale returns are unchanged and the market is an imperfectly competitive market. Without loss of generality, this paper uses the proportion of capital and labor factors to indicate the position of the enterprise in 
the value chain. When an enterprise is located in the upstream of the value chain, the more importance it attaches to technology research and development, the higher the proportion of capital elements; the proportion of capital in the production link in the middle reaches relatively decreases, and the proportion of labor elements in downstream enterprises reaches the highest value chain.

- $\quad$ Premise and hypothesis 2 : Industry added value = total industrial output value-industry intermediate input. In the theoretical analysis, it is considered that the stipulated value-added rate is of little significance. Drawing on the description of valueadded by scholars such as Bian Yabin, this paper uses the profit rate to perform value-added Measured, other influencing factors such as taxes and fees and other added value are uniformly denoted by $\mathrm{u}$ for further study.

- Premise and Hypothesis 3: The industrial production strategy is to maximize industrial profits. It does not distinguish between sales behaviors such as import and export and domestic sales, and other risky behaviors are not considered.

First, consider the short-term situation, and derive the relationship between the industry profit margin $\partial \pi$ and $\mathrm{K} \mathrm{i} / \mathrm{L} \mathrm{i}$, that is, the relative situation of the ratio of capital to labor. The industry in the model mainly makes decisions about the Internet level of the enterprise. Assuming that the industrial Internet level is $\lambda, \lambda \in(0,+\infty)$, and the industrial Internet level is low, the cost of information between industries is high, which is not conducive to cost savings. At the same time, it has a certain impact on industrial production time; The research considering the unit product effective level, and think that the product effective level (that is, the yield rate) is positively related to the Internet development level, set as $e^{\wedge}(-1 / \lambda)$, then $e^{\wedge}(-$ $1 / \lambda) \in(0,1)$. Assuming that the industrial labor and capital are constant, the total is $\mathrm{K}$ and $\mathrm{L}$; the learning cost needs to be paid before production, the upstream link focuses on product development, the learning cost is higher, the midstream link is the second, and the downstream link has the lowest learning cost, assuming $\mathrm{C}_{1}, \mathrm{C}_{2}, \mathrm{C}_{3}, \mathrm{C}_{1}>\mathrm{C}_{2}>\mathrm{C}_{3}$. The cost of learning is proportional to the amount of capital and labor. The greater the number of labor, the higher the cost of learning, and the more industrial capital, the greater the cost of learning. To distinguish the unit learning cost between labor and capital, let $\mathrm{Ci}=\mathrm{yi} \mathrm{Ki}+\mathrm{zi} \mathrm{Li}$; the industrial production function be introduced into the Cobb Douglas production function, $\mathrm{Y}=\mathrm{e}^{\wedge}(-1 / \lambda) \mathrm{A}(\lambda, \mathrm{t})$ $\mathrm{K}^{\wedge} \alpha \mathrm{L}^{\wedge} \beta \mu$, where $\mathrm{A}(\lambda, \mathrm{t})$ reflects the technical level of production, including the industry's Internet development level and other technical factors. $\alpha$ and $\beta$ represent the share of labor and capital in total production, respectively, $\alpha+\beta=1$ and $0<\alpha, \beta<1$.

According to the assumptions, the profit function of the corresponding industry can be expressed as

$$
\pi_{i}\left(L_{i}, K_{i}\right)=P * Y-\left(w L_{i}+q K_{i}+C_{i}\right)(1-
$$$$
\left.e^{-\frac{1}{\lambda}}\right)
$$

$$
i=1,2,3
$$

\subsubsection{Value-added curve shape analysis}

Let the unit cost of labor and capital be $\mathrm{w}$ and $\mathrm{q}$, respectively, and bring the production function and each index into formula (1) and simplify it, the profit rate is

$$
\begin{gathered}
R_{\Pi i}=1-\frac{q K_{i}+w L_{i}+z_{i}\left(K_{i}+L_{i}\right)}{P \mu e^{-\frac{1}{\lambda}} A(\lambda, t) L_{i}^{\beta} K_{i}^{\alpha}}\left(1-\mathrm{e}^{-\frac{1}{\lambda}}\right) \\
i=1,2,3
\end{gathered}
$$

As can be seen from the above formula, the level of Internet development can affect the value-added of the industry through three ways, namely, directly reduce the production cost $(w \mathrm{Li}+\mathrm{qKi}+\mathrm{Ci}) \mathrm{e}^{\wedge}(-1 / \lambda)$ to directly promote the production of manufacturers; or by increasing the information channels, Increase the degree of correspondence between product supply and demand, and change the yield rate $\mathrm{e}^{\wedge}(-1 / \lambda)$; Finally, the development of the Internet belongs to technological level progress, which is reflected in the production function $\mathrm{A}(\lambda, \mathrm{t})$.

Substitute $\alpha+\beta=1$ and $0<\alpha, \beta<1$ into the formula, and divide by $\mathrm{L}_{-} \mathrm{i}$ to get the following formula

$$
\begin{aligned}
R_{\Pi i} & =1-\frac{\left(q+z_{i}\right) \frac{K_{i}}{L_{i}}+\left(w+z_{i}\right)}{P \mu e^{-\frac{1}{\lambda}} A(\lambda, t)\left(\frac{K_{i}}{L_{i}}\right)^{\alpha}}\left(1-e^{-\frac{1}{\lambda}}\right) \\
i & =1,2,3
\end{aligned}
$$

According to the principle of optimization, $K_{-} i / L_{-} i=$ $\left(\mathrm{w}+\mathrm{z}_{-} \mathrm{i}\right) \alpha /\left(\mathrm{q}^{+} \mathrm{z}_{-} i\right) \beta$; that is, there is a production threshold between the level of added value and the input of production factors such as capital and labor. Find the second derivative

$$
\begin{aligned}
& \frac{\partial^{2} \Delta \pi_{\mathrm{i}}}{\partial\left(\frac{k_{i}}{L_{\mathrm{i}}}\right)^{2}}= \\
& \frac{\alpha\left(1-\mathrm{e}^{-\frac{1}{\lambda}}\right)}{P \mu \mathrm{e}^{-\frac{1}{\lambda}}} \frac{K_{i}}{L_{i}}{ }^{-\alpha-2}\left[\left(q+z_{i}\right) \beta \frac{K_{i}}{L_{i}}-\left(w+z_{i}\right)(\alpha+1)\right], \\
& i=1,2,3
\end{aligned}
$$

It is easy to know from equation (3) that when $\mathrm{K} i / \mathrm{Li}>((\mathrm{w}+\mathrm{zi})(\alpha+1)) /(\mathrm{q}+\mathrm{zi}) \beta$ is satisfied, the function is a concave function, otherwise it is a convex function. Of course, the change of the convexity and concaveness of the function is also related to the elasticity of capital, labor, and profit, and the case where the elasticity is zero is not considered here. Based on the above analysis, the relationship between $\Delta \pi \mathrm{i}$ and $\mathrm{Ki} / \mathrm{Li}_{\text {can }}$ be drawn as shown in Figure1.

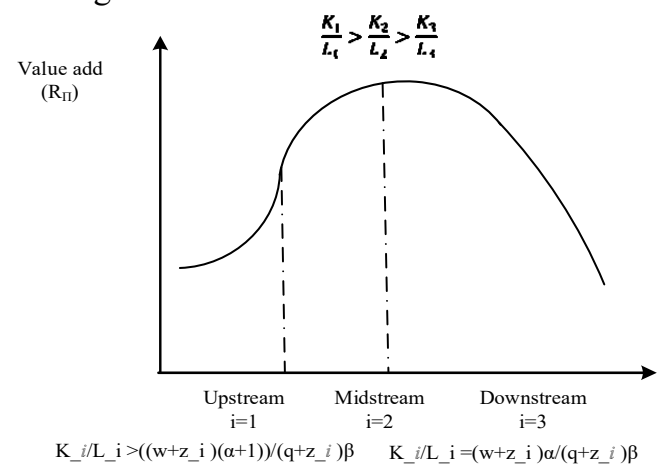

Fig1. The relationship between added value and the relative ratio of capital and labor 
It can be seen from Figure 1 that the curve obtained from the analysis of the Cobb Douglas production function roughly conforms to the analysis of the Musashi curve for the change in profit. The assembly and manufacturing links can enjoy higher profits, while the profits in parts, materials, and service links may be relatively higher. low. But there are the following differences, the production link is from $\mathrm{i}=1$ to $\mathrm{i}=3$, the ratio of the three links $\mathrm{Ki} / \mathrm{Li}$ keeps decreasing, at the point $\mathrm{K} i / \mathrm{Li}$ $=((\mathrm{w}+\mathrm{zi})(\alpha+1)) /(\mathrm{q}+\mathrm{z} i)$ On the left side of $\beta$, the increase in value increases faster, while on the right side, the increase in value increases slower. At the point $\mathrm{K} i / \mathrm{Li}=$ $(\mathrm{w}+\mathrm{zi}) \alpha /(\mathrm{q}+\mathrm{zi}) \beta$, the increase in value reaches the maximum. After that, it began to decline. Nakamura Suehiro proved that the Musashi curve is more in line with the natural monopoly industry. Since the above analysis takes the entire industry as the main body and aims to maximize the profit of the entire industry, other manufacturers have no incentive to enter the industry, so they are more in line with the Musashi curve. Features, such as Intel's production, meet this feature. At the same time, the analysis coincides with some industries analyzed by Zheng Jianzhuang and others, such as special equipment manufacturing, communications and other electronic equipment manufacturing value chain curves. Finally, the analysis is consistent with the theory of factor input, that is, when the factor is initially input, the output is greater and the profit rate is higher. The ratio of factor input in the manufacturing sector is more reasonable, and the profit rate may be higher.

\subsubsection{Analysis of the Influence of Internet Development on Value-added}

From formula (2), the improvement of Internet development level also affects the added value of the industry through three ways. First, the production cost is reduced, which directly promotes the production of manufacturers and increases the added value of the industry; secondly, the industrial information channels with high Internet level are unobstructed, the degree of correspondence between product supply and demand is increased, and the final level of marketable products $\mathrm{e}^{\wedge}(-$ $1 / \lambda)$ increases Finally, the advancement of technological level will also increase the production of products, making the overall rise of (2).

At the same time, by extracting the common factor from formula (2), the coefficient of the degree of influence on the Internet is

$$
\frac{1-\mathrm{e}^{-\frac{1}{\lambda}}}{\mathrm{e}^{-\frac{1}{\lambda}} A(t, \lambda)}
$$

Further analysis, the formula (4) is divided into two parts $\left(1-e^{\wedge}(-1 / \lambda)\right) / e^{\wedge}(-1 / \lambda)$ and $1 / \mathrm{A}(\mathrm{t}, \lambda)$, which is obviously available as the Internet develops The increase of the level $\lambda$ has decreased in both parts. After the negative value before (2), the improvement of the Internet development level will promote the increase of the added value of the industry. It is generally believed that $1-e^{\wedge}(-1 / \lambda)<e^{\wedge}(-1 / \lambda)$ $\mathrm{A}(\mathrm{t}, \lambda)$, the level of the Internet plays a magnifying role in the change of the added value, making the gap more obvious, reflected in the image In the Figure 2.

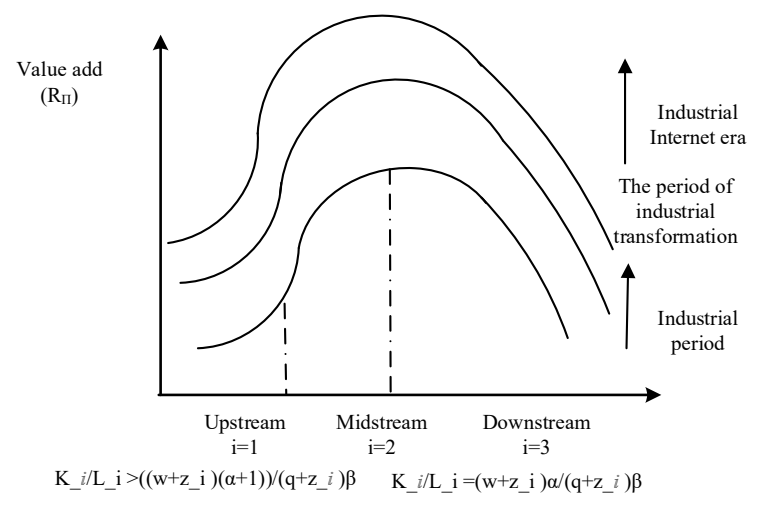

Fig2. Evolution path of value-added curve

\section{Conclusions and policy recommendations}

First, based on the analysis of the Internet Economy Outlook [6] of the European Union in 2012, this paper expands the analysis of the Internet and value chain association mechanism. On the basis of existing research, the ways and means of influencing the Internet on the global value chain to add further.

As for how the Internet promotes the growth of the value-added rate, Kee, $\mathrm{H}$. and Tang, $\mathrm{H}$ [7] have shown that Internetization can promote the relevance of global value chains by reducing transaction costs. Transaction costs include transportation costs, communication costs, and information costs. Relying on Internet big data, sellers can accurately locate buyers across regions and across borders through accurate search. Using B2B and B2C makes it easier and significantly reduces information costs.

At the same time, industrial Internetization promotes value chain association by reducing transaction time. In modern international trade, the time element of the transaction becomes more and more important. The Internet not only helps companies find suitable buyers and sellers, quickly order and deliver goods, but also helps companies complete rapid declaration forms and complete electronic customs declarations. Finally, Internetization has reduced the importance of the spatial distance level and expanded the importance of network distance. The reduction in transaction costs, the reduction in time, and the decrease in space dependence make it possible to refine the division of labor, increase the trade in intermediate goods, and thus increase the value chain.

In summary, the Internet substantially promotes trade by reducing transaction costs, transaction time and distance, and slenderness promotes the rise of the value chain.

\section{Acknowledgment}

This thesis was completed with the careful guidance and strong support of my tutor. From the beginning of writing to the finalization of the thesis, it took more than two months. I thank my teacher from the heart; at the same time, I also want to thank Beijing Jiaotong University for 
me Provided a unique research perspective, so that I can make progress; in the end, I would like to thank my family for their company and thank them.

\section{References}

1. Bakos, J. Y. "Reducing buyer search costs: implications for electronic marketplaces," Management Science. vol. 43 pp. 1676-1692, July 1997.

2. Anderson, J. and Wincoop, E. "Journal of economic literature," Trade Costs.New York, vol. 42, pp. 691 751, August 2004 .

3. Melitz, M .J "The impact of trade on Intra - Industry reallocations and aggregate industry productivity," Econometrica, London. vol. 71 , pp. 1695 - 1725, January 2003 .

4. Johnson R C, Noguera G. "Accounting for intermediates: production sharing and trade in value added". Journal of International Economics, New York, vol. 86, pp. 224-236, April 2012.

5. Koopman R, Powers W,Wang Z. "Give Credit Where Credit is Due:Tracing Value Added in Global Production Chains." National Bureau of Economic Research, 2010.

6. OECD . "OECD Internet Economy Outlook." Oecd, 2012 .

7. Kee, H . and Tang, H. "Domestic value added in exports: theory and firm evidence from China." The American Economic Review, Robert A. Moffitt vol. 106 :1402 - 1436, July, 2016. 